\title{
Strategi Satuan Pengawas Internal untuk Meminimalisasi Temuan (Studi kasus pada Perguruan Tinggi Keagamaan Islam Negeri A)
}

\author{
Helti Nur Aisyiah \\ IAIN Surakarta \\ e-mail: aisyah76@gmail.com
}

\begin{abstract}
This study aims to find out how the internal auditor (SPI) in Islamic College (PTKIN) A works. This research chose SPI PTKIN A due to the achievement of SPI PTKIN A which succeeded in obtaining zero findings on examination object in 2016 previously audited by SPI. Based on the research result, SPI PTKIN A has initiated the concept of pre-audit, current-audit, and post-audit on every activity contained in the working plan and budget of the ministry and institution (RKAKL) of fiscal year 2016. With these three concepts make SPI successfully suppress fraud and minimize the findings.
\end{abstract}

Keywords: audit, internal control unit, fraud, findings

(Aisyiah, 2019)

Aisyiah, H. N. (2019). Strategi Satuan Pengawas Internal untuk Meminimalisasi Temuan (Studi kasus pada Perguruan Tinggi Keagamaan Islam Negeri A). Moneter, 6(2), 11-16.

\section{PENDAHULUAN}

Sejak terbitnya Peraturan Menteri Agama (PMA) Nomor 25 Tahun 2017 tentang Satuan Pengawasan Internal (SPI) di lingkungan Perguruan Tinggi Keagamaan Islam Negeri (PTKIN), maka setiap PTKIN pun mulai membentuk dan mengoperasikan lembaga tersebut. Namun, pembentukan di lingkungan PTKIN bukanlah hal yang baru bagi beberapa PTKIN yang sudah memiliki SPI sebelumnya. Salah satunya adalah PTKIN A yang sudah memiliki SPI sejak tahun 2015. Selama tahun 2015 hingga 2017, SPI yang berada di PTKIN A ini, mulai memperlihatkan prestasinya. Adapun prestasi yang diperoleh selang dua tahun berdirinya SPI, yaitu pada saat kedatangan auditor eksternal pada tahun 2017 dalam rangkaian kegiatan audit objek pemeriksaan tahun 2016. Prestasi yang dimaksud adalah dengan adanya nol temuan pada objek pemeriksaan yang sebelumnya telah diaudit oleh SPI.

Prestasi yang diraih oleh PTKIN A membenarkan pernyataan (Sawyer, 2003) yang mengatakan bahwa audit internal yang efektif dapat membantu manajemen dengan memberikan analisa, penilaian, dan saran mengenai kegiatan yang diperiksanya. Pernyataan tersebut tersirat dari serangkaian kinerja SPI selaku auditor internal. Menurut (Zamzami, Faiz; Faiz, 2016), auditor internal berperan penting dalam melakukan manajemen risiko yang meliputi proses mengindentifikasi dan mengukur risiko, serta menyusun strategi untuk mengelolanya. Adapun kesalahan pengelolaan risiko dapat berpengaruh kepada jumlah temuan.

Penelitian ini dilakukan untuk mengetahui bagaimana SPI di PTKIN A bekerja hingga mampu mendapatakan nol temuan pada kegiatan audit yang dilakukan oleh auditor eksternal. Untuk mendapatkan prestasi nol temuan, pasti ada strategi yang digunakan untuk mendapatkannya.

Apa yang dilakukan oleh SPI merupakan wujud kesungguhan pengelolaan negara yang tidak hanya mengutamakan serapan anggaran, melainkan juga kehati-hatian. Keberadaan SPI menjadi salah satu alat dalam melakukan pengawasan dalam menjamin tujuan dan aktivitas manajemen berjalan dengan baik dan bebas dari kecurangan (fraud). (Asy'ari, Prasetyono, \& Hartadi, 2013) mengatakan bahwa

Fraud merupakan suatu istilah umum yang di dalamnya termasuk semua aneka sarana, kegiatan, dan kecerdikan yang dilakukan oleh seorang individu untuk mendapat keuntungan dari pihak lain, tetapi dengan representasi yang salah (Albrecht, Albrecht, Albrecht, \& Zimbelman, 2012). Pada dasarnya, tidak ada definisi atau aturan pasti mengenai dalil umum dalam mendefinisikan fraud. Hal ini dikarenakan fraud meliputi tindakan yang mengejutkan, tak terduga, menipu, licik, dan caracara yang tidak adil lainnya di mana pihak lain tercurangi. Siapa pun dapat melakukan dan terlibat dalam fraud karena pelaku fraud biasanya tidak dapat dibedakan dari orang lain atas dasar demografi atau karakteristik psikologis.

Terdapat pola fraud yang menjadi temuan BPK, yaitu: perawatan kendaraan bermotor; cetak dan penggandaan; pemeliharaan alat kantor dan rumah tangga; makanan dan minuman pegawai; makanan dan minuman tamu; makanan dan minuman rapat; Alat Tulis Kantor (ATK); Bahan Bakar Minyak (BBM); alat listrik; bahan atau material; dekorasi; dokumentasi; materai; pemeliharaan; pakaian; peralatan/ bahan kebersihan; sewa, barang/jasa 
badan layanan umum daerah; pigura; trophy; dan makan minum kepala dan wakil kepala daerah. (Sholihah, Siti; Alim, M. Nizarul; Musyarofah, n.d.)

Kecenderungan oknum melakukan fraud mendorong pemerintah untuk membuat solusi untuk mencegah dan mengatasi penyakit tersebut. Salah satu solusinya adalah dengan kewajiban membentuk SPI di lingkungan PTKIN. Solusi yang diberikan oleh pemerintah dengan sebaiknya juga diikuti dengan solusi internal PTKIN. Hal ini mengingat betapa pentingnya SPI dalam mewujudkan tata kelola yang baik di PTKIN tersebut. Menurut (Zarkasyi, 2008), SPI bertanggung jawab kepada rektor dan seluruh unit kerja yang membawahi tugas pengawasan internal. SPI tersebut berfungsi dan bertugas membantu rektor dalam memastikan pencapaian tujuan dan misi universitas dengan: (1) Melakukan evaluasi terhadap pelaksanaan program universitas; (2) Memperbaiki efektivitas proses pengendalian risiko; (3) Melakukan evaluasi kepatuhan universitas terhadap peraturan universitas dan perundangundangan; (4) Memfasilitasi kelancaran pelaksanaan audit oleh auditor eksternal.

\section{METODOLOGI PENELITIAN}

Penelitian ini menggunakan metode kualitatif yang nantinya akan menghasilkan data deskriptif berupa kata-kata tertulis atau lisan dari orang-orang atau perilaku yang diamati (Bowker, Bogdan, \& Taylor, 2006). Data hasil penelitian tersebut digunakan untuk mengetahui jawaban atas realitas tertentu (Afrizal, 2016). Realitas yang ada pada tahap pra penelitian, peneliti menemukan bahwa PTKIN A berhasil mendapatkan nol temuan pada objek pemeriksaan tahun 2016 yang dilakukan oleh auditor eksternal.

Fenomena langka, nol temuan, membuat peneliti ingin mengetahui bagaimana fenomena tersebut dapat terjadi. Dengan demikian, peneliti memusatkan metode kualitatif pada strategi studi kasus deskriptif. Dalam penelitian studi kasus, pertanyaan penelitian difokuskan untuk menjawab pertanyaan "bagaimana" dan "mengapa" (Yin, 2010). Harapan peneliti menggunakan strategi ini agar jawaban atas penelitian dapat sesuai dengan tujuan awal, yakni mengetahui bagaimana kinerja SPI hingga mampu memperoleh nol temuan pada PTKIN A.

Objek yang dipilih peneliti adalah SPI pada PTKIN A karena berperan sebagai auditor internal pada perguruan tinggi tersebut. Penelitian dilakukan dengan teknik wawancara kepada sekretaris, verifikator, dan auditor SPI yang telah dilakukan pada tanggal 23 Maret 2017 di kantor SPI PTKIN A. Adapun peneliti memilih objek wawancara tersebut karena dinilai yang paling menguasai informasi terkait kinerja SPI dalam meminimalisasi temuan. Untuk mendukung hasil wawancara, peneliti memperdalam informasi dengan telaah pustaka yang diperoleh dari sumber primer dan sekunder.

\section{HASIL DAN PEMBAHASAN}

SPI di PTKIN A sudah mulai berdiri sejak awal tahun 2015 bersamaan dengan terbitnya Surat Keputusan (SK) rektor tentang pengangkatan kepala dan sekretaris SPI. Setelah terbit SK yang diikuti dengan pelantikan ketua dan sekretaris SPI dilantik, disusunlah konsep baru dalam dunia audit internal, yaitu dengan melakukan tiga kali, yaitu pra, proses, dan pasca kegiatan. Kegiatan yang dimaksud adalah semua kegiatan yang tertulis di dalam Rencana Kerja dan Anggaran Kementerian dan Lembaga (RKAKL).

Ketiga konsep yang digagas oleh SPI PTKIN A memiliki karakteristik yang berbeda: (1) audit pra kegiatan (pre-audit) dilakukan dengan cara memeriksa proposal kegiatan; (2) audit proses kegiatan (current-audit) dilakukan dengan mengamati pelaksanaan kegiatan; (3) audit pasca kegiatan (post-audit) dilakukan dengan memeriksa laporan pelaksanaan kegiatan dengan dilampiri bukti-bukti transaksi keuangan.

Pelaksanaan ketiga jenis audit tersebut dilakukan dengan spesialisasi kerja. Hal ini dilakukan agar masing-masing personel SPI dapat bekerja dengan maksimal dan terfokus pada satu bidang. Dengan demikian, SPI PTKIN A yang beranggotakan 10 orang membagi pekerjaan menjadi beberapa bagian:
a. 1 orang ketua;
b. 1 orang sekretaris;
c. 4 orang verifikator;
d. 3 orang auditor;
e. 1 orang staf administrasi.

Auditor yang terdiri dari 3 orang, masing-masing auditor memiliki satu tanggung jawab audit:

a. keuangan;

b. Barang Milik Negara (BMN);

c. kinerja atau Sumber Daya Manusia (SDM).

Untuk mempermudah garis komando, maka SPI PTKIN mempunyai struktur organisasi seperti gambar 1 berikut. 


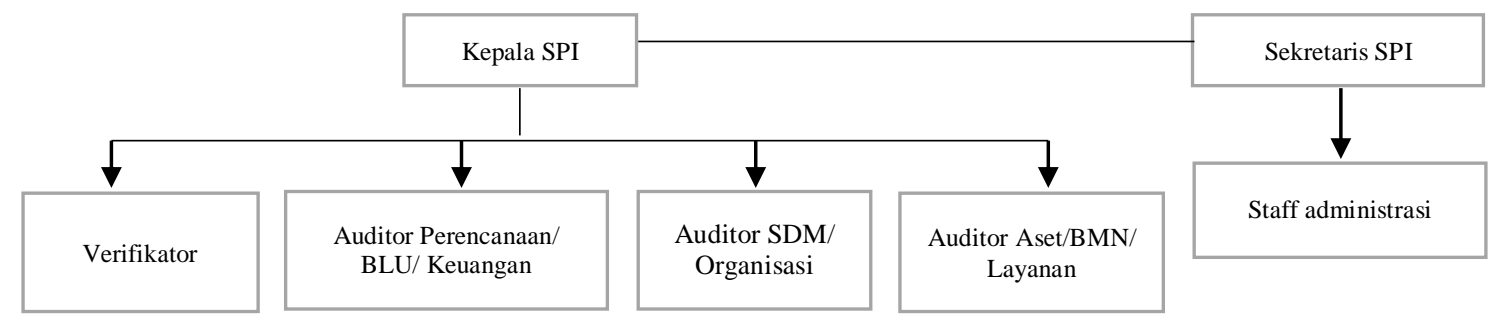

Sumber: Buku Pedoman Satuan Pengawas Internal PTKIN A, 2016

\section{Gambar 1. Struktur Organisasi PTKIN A}

Penempatan posisi tersebut disusun berdasarkan kebutuhan, kompetensi, dan pengalaman dalam pengelolaan keuangan negara. Jabatan verifikator diduduki oleh tenaga kependidikan, sedangkan auditor oleh dosen yang sesuai dengan keilmuannya, yaitu lulusan di bidang akuntansi. Untuk mendukung kinerja SPI yang baru terbentuk, maka ada dua orang verifikator yang khusus didatangkan dari bagian keuangan pusat dan unit layanan pengadaan. Dengan dua orang verifikator yang berpengalaman dalam bidang keuangan dan pengadaan, SPI lebih mudah mengetahui risiko kecurangan yang telah terjadi bertahun-tahun di PTKIN A tersebut.

Berdasarkan struktur organisasi di atas, auditor terbagi menjadi tiga bagian: (1) perencanaan/ Badan Layanan Umum (BLU)/ keuangan; (2) Sumber Daya Manusia (SDM)/ organisasi; (3) aset/Barang Milik Negara (BMN)/layanan. Masing-masing posisi ditempati oleh satu orang, tetapi dalam pelaksanaan audit saling mendampingi. Jadi, yang bertanggung jawab atas posisi tersebut hanyalah satu orang, tetapi teknisnya dikerjakan secara bersama-sama.

Khusus pada kegiatan audit BMN, auditor bagian BMN menghadirkan pihak ketiga, yaitu tim Kantor Akuntan Publik (KAP). Hadirnya KAP diperlukan untuk mengaudit objek audit yang tidak dapat dijangkau oleh auditor internal karena keterbatasan kompetensi, terutama yang berkaitan dengan BMN. Jadi, pada saat audit BMN, tim auditor SPI PTKIN bertugas mendampingi tim KAP selama proses audit. KAP di sini juga sengaja didatangkan mengingat PTKIN A sudah berstatus Badan Layanan Umum (BLU).

\section{Proses Audit}

Audit yang dilakukan oleh SPI PTKIN A memiliki cara yang berbeda-beda. Adapun perbedaan dari ketiga jenis audit tersebut adalah, sebagai berikut.

a. Pre-audit

Audit pada jenis ini dilakukan pada dokumen pra kegiatan, yaitu proposal. Dalam dunia keuangan sektor publik, proposal diistilahkan dengan Kerangka Acuan Kinerja (KAK). Setiap akan melakukan pencairan dana kegiatan, setiap unit kerja harus membuat KAK terlebih dahulu untuk mengetahui rencana apa saja yang akan dilakukan untuk mencairkan dana tersebut. Adapun acuan dalam penyusunan KAK berdasarkan data yang telah ada di RKAKL.

SPI PTKIN A tidak memberikan format pasti pada $\mathrm{KAK}$, melainkan hanya mengaudit isi dari KAK tersebut. Berdasarkan konten atau isi yang ada dalam KAK, audit dilakukan berdasarkan kelengkapan dokumen, kewajaran harga, dan relevansi isi KAK terhadap jenis barang yang akan dibelanjakan. Adapun alur dari pemeriksaan pada KAK yang dilakukan SPI dapat dilihat pada gambar 2 berikut. 


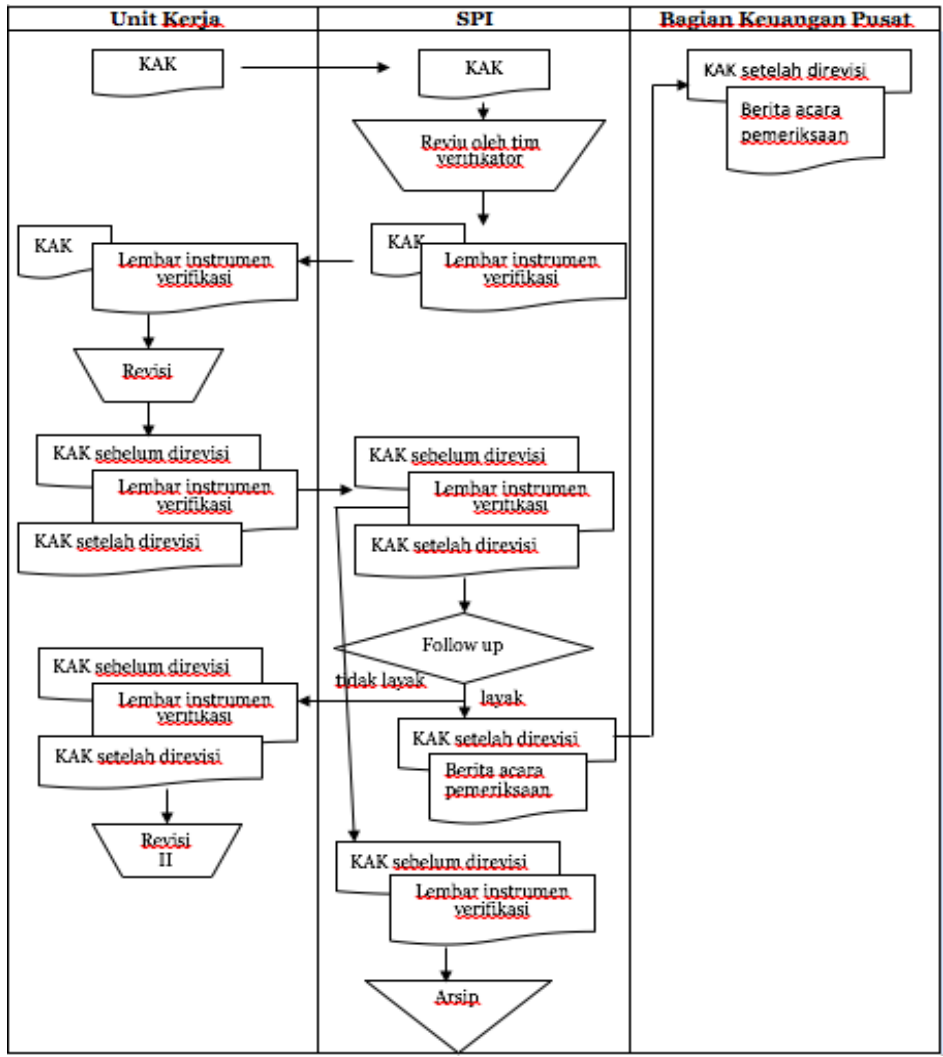

Sumber: Data primer yang dioleh, 2017

Gambar 2. Alur Pemeriksaan Kerangka Acuan Kerja

Berdasarkan bagan alir pada gambar 2, KAK yang sudah disusun oleh unit kerja, diserahkan ke SPI. Ada perbedaan pada sebelum dan sesudah adanya SPI. Sebelum ada SPI, KAK langsung diserahkan ke bagian keuangan pusat untuk kepentingan pencairan anggaran. Namun, semenjak adanya SPI, KAK harus masuk terlebih dahulu ke SPI untuk dilakukan preaudit.

Proses detailnya, KAK yang masuk ke SPI diverifikasi terlebih dahulu oleh tim verifikator. KAK yang masuk diperiksa oleh tim verifikator atau bersama auditor. Jadi, auditor baru akan memeriksa KAK jika ada yang perlu dikonsultasikan oleh tim verifikator. Jika verifikator bisa langsung menangani, maka bisa langsung dikembalikan ke unit untuk segera diperbaiki dengan menyertakan berita acara pemeriksaan.

Ada dua status yang dituliskan tim verifikator dalam berita acara, layak dan tidak layak. Jika catatan tim verifikator menunjukkan bahwa KAK sudah layak, maka tidak perlu kembali ke SPI lagi dan bisa langsung ke keuangan pusat untuk mengajukan pencarian anggaran. Namun, setelah berita acara pemeriksaan diketahui dan ditandatangai oleh auditor. Jika tidak layak, maka unit perlu memperbaiki KAK dan kembali lagi ke SPI hingga keluar berita acara pemeriksaan dengan status layak.

Selain dokumen, tim verifikator dan auditor juga melakukan audit faktual untuk memastikan kondisi lapangan yang sebenarnya. Audit faktual diperlukan untuk mengantisipasi dan mencegah adanya kesalahan yang tidak disengaja (ketidaktahuan) maupun yang disengaja (kecurangan). Ada beberapa teknik yang dilakukan, yaitu dengan mencari sumber primer dan sekunder. Sumber primer dilakukan dengan langsung menemui rekanan kerja atau melalui media komunikasi, sedangkan sumber sekunder dilakukan dengan mencari informasi dari media cetak atau digital.

Dalam melakukan audit pra kegiatan, tim SPI berpedoman pada Peraturan Menteri Keuangan (PMK) tahun berjalan tentang standar biaya masukan. Namun, tidak semua akun termuat dalam PMK tersebut. Untuk mengatasi masalah tersebut, tim SPI perlu menyusun sendiri daftar acuan belanja yang sering digunakan dalam kegiatan. Misalnya, tim SPI melakukan survey harga alat tulis kantor untuk menentukan batas harga maksimal barang yang dianggap wajar.

Proses pre-audit yang sedemikian rupa dilakukan untuk mencegah adanya fraud yang nantinya akan benar-benar dilaksanakan berdasarkan isi dari KAK tersebut. Menurut (Aisyiah \& Ahzar, 2017), potensi fraud yang paling sering ditemukan pada KAK adalah: harga satuan melebihi standar biaya masukan; item belanja tidak rinci; ketidaksesuaian anggaran dengan rundown acara; penggunaan satuan. Harga melebih satuan ditunjukan dengan 
adanya harga yang melebihi standar biaya pada masukan. Misalnya, makan seharusnya 30 ribu rupiah, di Rencana Anggaran dan Belanja (RAB) melebihi dari nominal tersebut.

\section{b. Current-audit}

KAK yang dianggap layak belum tentu layak pada ranah proses berlangsungnya kegiatan yang termaktub dalam KAK tersebut. SPI yang mempunyai fungsi mengawasi pun tetap harus mengawasi berjalannya kegiatan. Audit proses dilakukan untuk memastikan informasi yang ada di KAK benar-benar terlaksana, tidak dikurangi dan tidak ditambahi.

Adapun teknik audit proses dilakukan dengan pengamatan langsung, dokumentasi, atau menghubungi orang yang bersangkutan media komunikasi. Pengamatan langsung dilakukan dengan tim SPI mengirimkan seorang yang ditugaskan untuk melihat kegiatan tersebut secara langsung yang kemudian hasil pengamatannya ditulis ke dalam berita acara.

Dalam pengamatan langsung, ada saatnya proses audit tersebut di luar kemampuan auditor internal, sehingga perlu mengundang KAP untuk melakukan audit fisik, terutama pada Barang Milik Negara (BMN). Untuk teknik dokumentasi, tim SPI yang bertugas meminta ketua pelaksana kegiatan untuk mendokumentasikan setiap kegiatan dan barang yang termuat dalam Rencana Anggaran Belanja (RAB) di KAK. Hasil dokumentasi tersebut langsung dikirimkan ke anggota tim SPI yang bertugas melalui media komunikasi yang disepakati kedua belah pihak.

Selain kedua teknik tersebut, menghubungi orang yang bersangkutan dengan media komunikasi juga penting. Misalnya, anggota tim SPI yang ditugaskan sengaja menelepon narasumber kegiatan untuk memastikan apakah jumlah jam mengisi kegiatan (JPL) sudah sesuai dengan yang tercantum dalam KAK.

\section{c. Post-audit}

Proses audit pasca kegiatan sama dengan audit pra kegiatan, yaitu dokumen pasca kegiatan diaudit terlebih dahulu oleh SPI hingga dinyatakan layak untuk bisa disampaikan ke bagian keuangan pusat. Pada audit ini, tidak selama dan seketat audit pra kegiatan. Hal ini dikarenakan dokumen pasca kegiatan hanya menyalin dan menjabarkan isi KAK yang sudah disusun sebelumnya, sehingga tim verifikator tinggal membandingkan isi KAK dengan dokumen pasca kegiatan dengan didukung data-data hasil current-audit. Adapun dokumen pasca kegiatan berupa Laporan Pelaksanaan Kegiatan (LPK) dan Laporan Pertanggungjawaban (LPJ) ${ }^{1}$.

Kegiatan audit pasca kegiatan bisa dilakukan secara rutin sama seperti alur KAK masuk SPI atau juga bisa dilakukan secara langsung di unit kerja. Jika audit pasca dilakukan rutin, maka dokumen pasca kegiatan disampaikan ke SPI untuk diverifikasi.

\section{Hambatan Audit}

Hambatan pada awal berdirinya lembaga SPI adalah adanya beberapa orang atau lembaga yang merasa keberatan dengan pola kerja audit yang ditetapkan oleh SPI. Namun, dengan dukungan penuh dan komitmen dari Rektor PTKIN A, maka masalah tersebut dapat terpecahkan. Konflik yang sempat ada kembali harmonis setelah auditor eksternal mengumumkan hasil auditnya yang menekankan bahwa ada sebanyak nol temuan pada objek pemeriksaan yang sudah diperiksa oleh SPI. Dengan demikian, jelas ada efek baik dengan adanya SPI pada pengelolaan keuangan di PTKIN A.

\section{KESIMPULAN}

Proses audit yang terkonsep dan terlaksana dengan baik menjadikan SPI PTKIN A berhasil membuat prestasi yang maksimal. Objek nol temuan tersebut merupakan objek yang sebelumnya sudah diaudit oleh SPI. Dengan munculnya nol temuan, maka jelas ada perbedaan antara sebelum dan sesudah dibentuknya SPI. Jumlah temuan setelah adanya SPI jelas lebih sedikit dari pada sebelum adanya SPI. Dengan demikian, benar adanya bahwa SPI mampu menekan fraud dan jumlah temuan. Apalagi, jika dilihat dari proses audit dari pra, proses, hingga pasca kegiatan yang sangat detail yang jelas menjadikannya tidak sia-sia menuju predikat nol temuan pada objek audit yang telah diaudit oleh SPI PTKIN A.

Dengan adanya artikel ini, diharapkan perguruan tinggi baik di bawah Kementerian Agama (Kemenag) maupun Kementerian Riset dan Teknologi (Kemenristek) dapat melakukan benchmark pada apa yang telah dilakukan oleh tim SPI PTKIN A. Dengan demikian, akan tercapai good governance dan clean government di dunia perguruan tinggi Indonesia.

\section{REFERENSI}

Afrizal. (2016). Metode Penelitian Kualitatif: Sebuah Upaya Mendukung Penelitian Kualitatif dalam Berbagai Disiplin Ilmu. Jakarta: PT RajaGrafindo Persada. 
Aisyiah, H. N. (2019). Strategi Satuan Pengawas Internal untuk Meminimalisasi Temuan (Studi kasus pada Perguruan Tinggi Keagamaan Islam Negeri A). Moneter, 6(2), 11-16.

Aisyiah, H. N., \& Ahzar, F. A. (2017). Ex Ante Audit Sebagai Upaya Pencegahan Fraud. AKRUAL: Jurnal Akuntansi. https://doi.org/10.26740/jaj.v9n1.p54-64

Albrecht, W. S., Albrecht, C. O., Albrecht, C. C., \& Zimbelman, M. F. (2012). Fraud Examination. South-Western Cengage Learning. https://doi.org/10.1017/CBO9781107415324.0 04

Asy'ari, M. A., Prasetyono, \& Hartadi, B. (2013). Peran dan Fungsi Pengawasan Intern dalam Pencegahan FRaud Pada Perguruan Tinggi X. Jaffa.

Bowker, L. H., Bogdan, R., \& Taylor, S. J. (2006). Introduction to Qualitative Research Methods: A Phenomenological Approach to the Social
Sciences. Teaching Sociology. https://doi.org/10.2307/1317067

Sawyer, L. B. (2003). Sawyer's Internal Auditing: The Practice of Modern Internal Auditing. The Institute of Internal Auditors.

Sholihah, Siti; Alim, M. Nizarul; Musyarofah, S. (n.d.). Memotret Pola Fraud pada Rincian Objek Belanja yang Menjadi Temuan BPK, 4(2), 101-110. https://doi.org/http://dx.doi.org/10.21107/jaffa. v4i2.2783

Yin, R. K. (2010). Studi Kasus: Desain dan Metode. Qualitative Research.

Zamzami, Faiz; Faiz, I. A. M. (2016). Audit Internal: Konsep dan Praktik. Yogyakarta: UGM Press.

Zarkasyi, M. W. (2008). Good Corporate Governance. Bandung: Alfabeta. 